\title{
Sub-classification Processes of the Cul-de-sac Courtyards
}

\author{
Anniz Fazli Ibrahim Bajunid 1, Mohamed Yusoff Abbas ${ }^{1}$, \\ Abdul Hadi Nawawi ${ }^{2}$, Alias Rameli ${ }^{3}$ \\ ${ }^{1}$ Centre for Environment-Behaviour Studies, \\ 2 Faculty of Architecture, Planning and Surveying, \\ Universiti Teknologi MARA (UiTM), Shah Alam, Malaysia \\ 3 International Policy Evaluation and Research Unit, Research And Development Division, \\ Federal Department of Town and Country Planning, Malaysia \\ toanniz@gmail.com
}

\begin{abstract}
Shah Alam has exhibited flourishing cul-de-sac courtyard neighbourhoods, which has stirred debatable interests. The objective of this paper is to continue the discourse in measurable analysis of subclassifications. The paper assembles physical data with key characteristics that make-up the physical construct of a cul-de-sac courtyard by administering measurements, observations and checklists. The sub-classification processes led to preliminary key factors such as density, size, design forms and user implications. 18 cul-de-sac courtyards in Shah were catalogued and inventoried, elucidating its syntax. The database introduced potential in longitudinal research of the socio-spatial micro-neighbourhood unit, towards pragmatic applications in emergent design practices.
\end{abstract}

Keywords: Cul-de-sac syntax; cul-de-sac courtyards; micro-communities; design practices

eISSN 2514-751X @ 2018. The Authors. Published for AMER ABRA cE-Bs by e-International Publishing House, Ltd., UK. This is an open-access article under the CC BY-NC-ND license (http://creativecommons.org/licenses/bync-nd/4.0/). Peer-review under responsibility of AMER (Association of Malaysian Environment-Behaviour Researchers), ABRA (Association of Behavioural Researchers on Asians) and $c E-B s$ (Centre for EnvironmentBehaviour Studies), Faculty of Architecture, Planning \& Surveying, Universiti Teknologi MARA, Malaysia DOI: https://doi.org/10.21834/aje-bs.v3i10.320 


\subsection{Introduction}

The creative, built-environment domain of Planners and Architects, typically faces numerous design typologies for residential planning. The design of neighbourhoods requires an infused and matured appreciation of the community within its own technical, social and cultural context. Developed nations, especially the United Kingdom, United States and Australia have amongst its housing developments, a historical and theoretical precedent of a category of residential planning of the cul-de-sac. However, beyond these nations, the design approaches and its implications to the very same category of residential planning, differ substantially and often lead to other classifications or syntax.

The notion of classifying these culs-de-sac neighbourhoods' syntax also suggests a micro understanding of each of the neighbourhoods. These micro-neighbourhoods, alludes to several aspects of commonality with each other but in essence also its individual, identifiable and measurable technical characteristics. In essence, this paper's objective shall endeavor to elucidate the classification processes of the cul-de-sac, within the scope of the Malaysian, Shah Alam City Council (SACC) district. The paper aspires at reporting the various sub-classifications available within the context of the Malaysian cul-de-sac courtyard neighbourhoods.

Relevant observations and international studies within the area of culs-de-sac, among others are of Asabere (1990), Charmes (2010), Cozens \& Hillier (2008), and especially of Southworth \& Ben-Joseph $(1995,1997)$ and Southworth \& Owens (1993). Some of these international studies are remarkable within western planning and policies but requires a different, localised contribution within the Malaysian scenario; such as the works of (Davis, et. al., 2006; Ghazali \& Bajunid, 2011; and Othman \& Said, 2012). This paper shall continue to offer further discussions, particularly to one specific investigation to the cul-de-sac courtyard neighbourhoods (Bajunid, et. al., 2012a, b, c, 2013). The limitations of this paper however, comprises of limited local literature on the subject matter (micro neighbourhoods) academically, compared to that available in practice.

\subsection{Literature Review}

\subsection{Relevant Literature Extraction}

Bajunid, et. al. (2012a, b, 2013) has also covered the breath of the literature sourcing to the immediate relevancy of the Malaysian context through an adapted a series of systematic reviews in his papers. It must be noted that this too, are limited by the time frame that the investigation was undertaken as digital mediums constantly evolves and expands. However, he did note that there was a continuous and systemised field of digital alerts to organize new and current data.

\subsection{Multi-disciplinary}

Within the realm of environment-behaviour, it could be assumed that the field traverses several academic domains, and this was justifiably so as the literature search demonstrated. 
The plurality of the neighbourhood sphere signifies the complexity and nature of the research. The trans-disciplinary research infers multiple future research potentials but requires stringent structure and control. This paper continues the works of Bajunid (2012b) of specific assessment method of identifying the cul-de-sac courtyards to classifying the neighbourhoods within the Shah Alam City Council. Themes of these macro- and microneighbourhood issues have been addressed by Bajunid, et. al., (2013).

\subsection{Methodology}

\section{Expanding Archives}

The literature search on the assessment methodology of identification and classification assembled a generous 38 literatures, potentially appropriate for review. However, only 17 were deemed useful by outcome, after the exclusion of literatures that did not relate to direct methodology.

Table 1: Literature Sieving Processes

Reviewed for identification and classification processes of the cul-de-sac. The percentages (\%) are only indicative of available and relevant extracted data in each stage of the filtering processes.

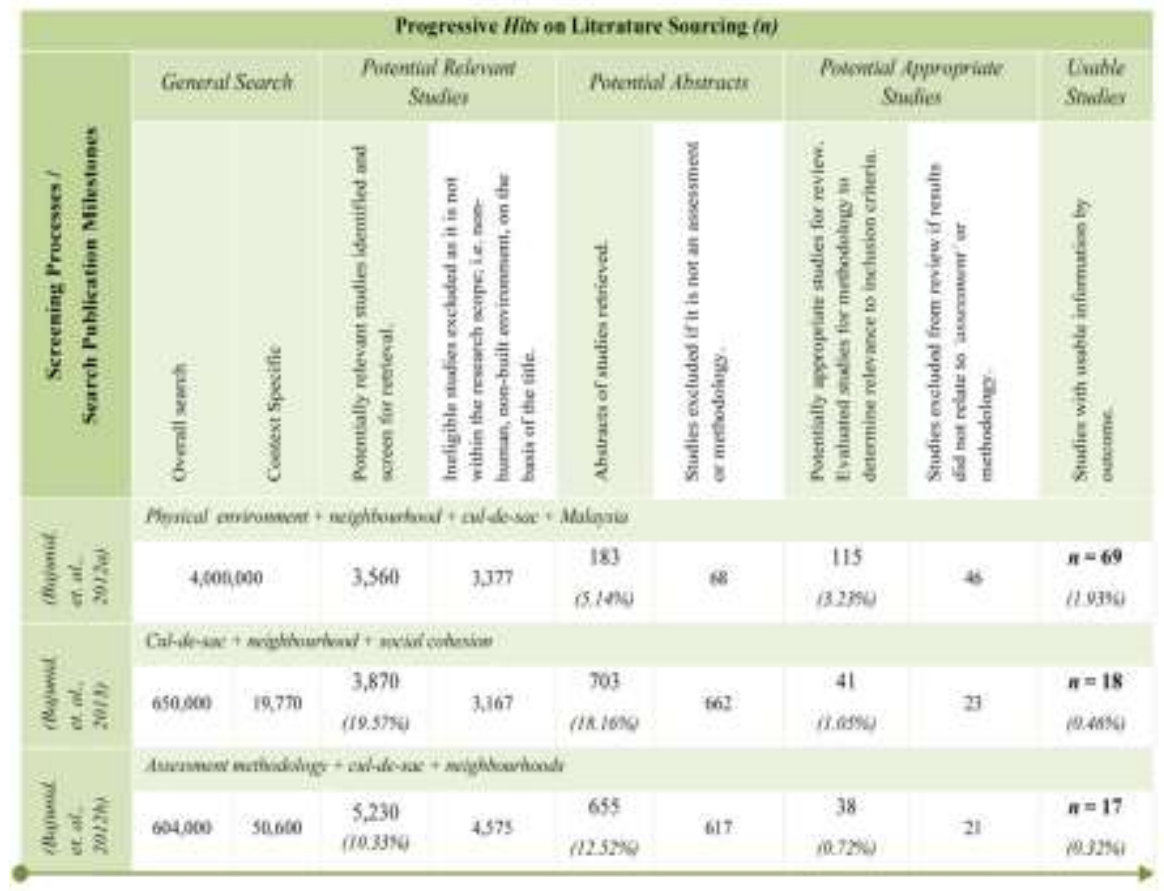

Source: Bajunid, et.al. (2012a, b, 2013)) 
These embodied literatures were from various academic publications and a specific PhD research on the cul-de-sac courtyard. Table 1 illustrates the sieving processes and relevancy of the assessment methodology of cul-de-sac. This illustration only intends to capture the breadth of available research, whilst maintaining focus on the local scene. It is evident that the local domain has yet to build its own published material on this discussion. It must be noted also that Table 1 does not reflect the entirety of unpublished sources. A number of these unpublished materials and other sources have been tabled in detailed by Bajunid, et. al., (2012b). Yet, even then, the processes of classification remain obscure and subjective.

This subjectivity is arguably uncommon as it represents inherent traits of the planning and architectural profession. The visual language or pedagogy justifies a common interpretation of the built environment, not immediately apparent to the mere nonprofessional of the built environment discipline. What seems to be a complex plan to the nonprofessional seems obvious to the trained architect or planner due to the visual language. However, not all these subjectivity are all subjective. There is a certain underlining coherency of hierarchy, structure, and technicality behind the esthetics. The cognitive pedagogy of the architectural and planning profession is not the focus of this paper but underlines the next segment of the discussion.

\subsection{Results and Discussions}

\subsection{From Identification towards Classification}

\subsubsection{Identification of the Cul-de-sac Courtyards}

The previous study of Bajunid et. al. (2012b) initiated the identification processes of a cul-desac within the municipality, based on these literature reviews. This was also made possible by the various maps of different scales obtained by the authors, digitally as well as manually via the local authority. The same author also met with relevant personnel in the local authority to substantiate the same process and findings within the local context of the SACC district (using reviews by Bajunid 2012b). This was done through a number of face-to-face meetings and correspondences.

In summary, the numerous discussions were quite disconcerting in the availability of relevant data of street and segment analysis (Bajunid, et. al., 2013) within the local scene. To expect classification, is even more inane as was used by other international research (Bajunid, 2012b). Upon retrospective, it was clear that within the local scenario, establishing any tangible data of the micro neighbourhood, (or even the cul-de-sac courtyard) would be greatly novel (Table 2). This was highly supported by the positive reactions and support garnered for the continuation of the research endeavour by the various authoritative personnel that were interviewed. There were however some sort of peripheral local documents that provided a sense that the authorities were also heading towards that shared direction with indications of the cul-de-sac as the preferred design in neighbourhood planning 
(Federal Department of Town and Country Planning, 2011; Selangor Department of Town and Country Planning, 2010).

The following findings, within the typical design terminology of the cul-de-sac courtyard, refer to the naturally formed courtyard within the cul-de-sac layout, with only one point of entry and exit. The site observation approach along with available data stipulated earlier shall delimit the scope and findings towards future triangulation purposes.

\subsection{Classifying the Cul-de-sac Courtyards}

\subsubsection{The Method of Inventory and Categorising}

In order to ascertain first that the actual cul-de-sac courtyard exists as seen by visual legibility in the digital and street maps, a physical visit was conducted to verify its location (Bajunid, et.al). This manual and physical method continued in the full assessment of all cul-de-sac courtyards in Shah Alam by three trained architects. In ensuring its validity amongst the architects, separate visits were also conducted separately and then discussed confirming its verdict. This continuous process of multiple site visits occurred between September 2011 to June 2012.

Subsequently, each cul-de-sac courtyard was photographed and catalogued visually and technically. As seen in two samples of a cul-de-sac courtyard in Figure 1, each of the 18 courtyards was documented visually. This documentation process is detailed further in Table 4 , but the sequence of this process could be clearly described (within the context of architectural pedagogy) as Site Analysis. Although the very notion of site analysis could be highly debatable in its different approaches, the fundamental essence and hierarchy was captured and shown in Table 4.

\subsubsection{Illustrating, Recording and Decoding}

It was also important to decipher these courtyards into technical terms. Each of the $18 \mathrm{cul}$ de-sac courtyards was interpreted and digitised via AutoCAD, a highly, technical software used by local and international conglomerates across the construction's various consultants. The software is a precise tool often used for specification and tendering of drawings. Due to the various limitations of different developers involved throughout the 35-year span of the 18 different culs-de-sac; the cul-de-sac courtyards were digitally overlapped and redrawn with triangulations of on-site surveys in ascertaining its measurements. With the industries standards and Uniform Building By-Law (UBBL), certain technical aspects of the layout could also be confirmed visually as well as technically. Though the internal area or footprint consistency of each of the houses could be disputed, this research only aims at discovering the external spaces or 'courtyard' within the cul-de-sac. It is important to highlight, as learnt by Bajunid, et. al. (2012a), that these in between spaces are often unnoticed, but vital within the micro neighbourhood setting.

Apart from the accuracy of the technical drawings, colour coding was implemented in determining and streamlining the various important land uses of each cul-de-sac courtyard neighbourhood (Figure 2). This digital re-identification and differentiating degree and intensity 
of the colouring simplifies and exhibits the necessary utility of each of these elements. Successively, after conceiving all the manual and digital technical settings, the cul-de-sac courtyards were personally visited and observed to ensure its absolute validity again.

\subsection{Summarising the Findings}

The process of the meticulous, digital documentation is repeated to all sites. Each of the 18 cul-de-sac courtyards has to be treated individually, to ascertain its objectivity. To this end, an apparent table consisting of various items or characteristics could be formed. The similarities and dissimilarities of the inherent characteristics of these culs-de-sac could be better grasped and appreciated.

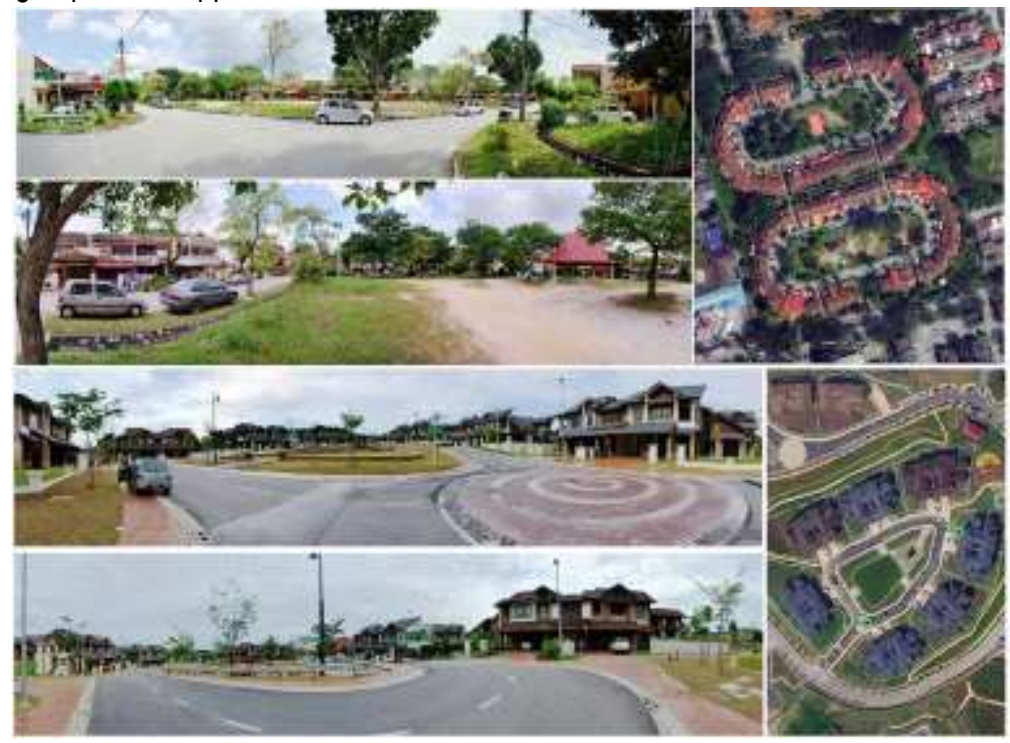

Figure 1: Technical Visual Analysis of Seksyen 18/5A, 14A and U8/74C.

Exemplifying the stark contrast of varying cul-de-sac courtyard arrangements and typology. Top right: Google Earth from 509m Eye Altitude of Seksyen 18. Top cul-de-sac - 18/14A, bottom cul-de-sac $18 / 5 \mathrm{~A}$ with corresponding panoramas. Bottom Right: Google Earth from $521 \mathrm{~m}$ Eye Altitude of Seksyen U8/74C (Bukit Jelutong), with panoramic street approaches into the cul-de-sac courtyard (left) (4th October 2011).

(Source: Author, 28 September 2011)

Table 3 illustrates just two from 18 different cul-de-sac courtyards within one comprehensive technical evaluation. A technical evaluation of this sort is typically termed as an audit, within common practice of an architectural consultancy. More so design oriented than theoretical, it does draw in several conjectures of academic and social importance. The technical findings are non-speculative as tabled, but the inferences on the social fabric of the micro neighbourhood are unfathomable, and require further research. 
Table 2: Identification Sieving Processes

Table illustrates the detailed sieving processes in identifying the cul-de-sac courtyards within the SACC jurisdiction, which consists of an estimated \pm 3180 street segments in 2011 . For complete explanatory notes and detail description on the visuals, please contact the Author or refer to unabridged version of the paper in Procedia - Social and Behavioural Sciences.

\begin{tabular}{|c|c|c|c|}
\hline \multirow{2}{*}{$\mathrm{N}_{0}$} & \multirow{2}{*}{ Processes } & \multicolumn{2}{|c|}{ Macro and Micro Identification Sieving } \\
\hline & & Map 4(Sieve 3) & Map 4 (Siete 4) \\
\hline 1 & Type of Map & Google Eath \& Googe Maps & Op-1ite Assesmentit \\
\hline 2 & Scurce \& Date & $\begin{array}{l}\text { Google (Inagen Date - 23 lanary } \\
\text { 2010. Retrieved berween 27-29 } \\
\text { Sopnember 2011) }\end{array}$ & $\begin{array}{l}\text { Ausermem condatid bet inen September } \\
2011 \text { - June } 2012\end{array}$ \\
\hline 3 & Seale: & Eye Altitude 2000 to $44 \mathrm{~lm}$ & On Site Alesumert \\
\hline 4 & Methodology Sequencing & \multicolumn{2}{|c|}{ 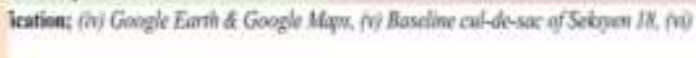 } \\
\hline 5 & Criteria & \multicolumn{2}{|c|}{ Manud and Diginl Mise Identifictim } \\
\hline & a. Streat Type (Sinet Autters) & \multicolumn{2}{|c|}{ Cul-desac } \\
\hline & b. No of Entry Points & \multicolumn{2}{|c|}{1 peint of Eatny } \\
\hline & c. Estimsted Green Size (in') & \multicolumn{2}{|c|}{$500 \mathrm{~m}^{2}-4000 \mathrm{~m}^{2}$} \\
\hline & d. Estimated House $\mathrm{Nos}$ & \multicolumn{2}{|c|}{$20-80$ terrace houses } \\
\hline & e. Grem / Counyard Visible & \multicolumn{2}{|c|}{ Green / Cuurtyands Viatile } \\
\hline 6 & $\begin{array}{l}\text { Nos of Neighboarhoods (Stret } \\
\text { Type) Identifiad }\end{array}$ & 9 Neighbourtoods in Rationy & 5 Neightbourhoods $188 \mathrm{Cob}$ - Aesad \\
\hline 7 & $\begin{array}{l}\text { Relevart Naighbourhoods A9? } \\
\text { Street in MBSA }\end{array}$ & $<1600 \Omega(1)$ & $<8930$ coses \\
\hline 8 & Further Assessment Required & Ys & No \\
\hline 9 & Neightbourboods Identified & 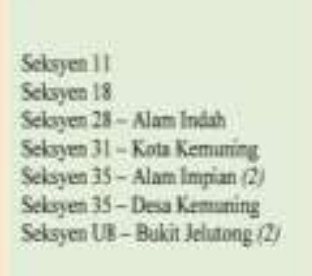 & 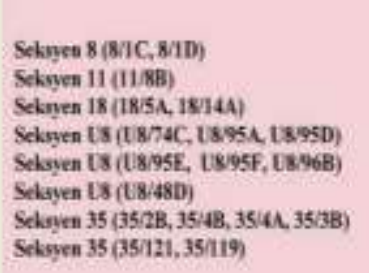 \\
\hline 10 & Notes & \multicolumn{2}{|c|}{$\begin{array}{l}\text { Visual assesmert adknouledyes Mips' Velidity and Verify Canert Statis of } \\
\text { Netightourhoods. }\end{array}$} \\
\hline
\end{tabular}

(Source: Table extracted from from a larger study from Bajunid, et. al. (2012b)) 
In general, development of the items and characteristics was almost mechanical and rather instantaneous. This would be justifiable, as though the layout may seem designed; there are similarities in realising such a construction technique. The conventions of housing and terraces remain historically the same, with manageable, subtle detailing in adhering to different typologies and concept.

The cul-de-sac courtyard layout mainly consists of an additional characteristic, the courtyard, surrounded by a limited number of housing units, with a single vehicular entrance. This one aspect could further be tabulated and calculated in detail by dividing the items into two main categories of technical and social characteristics. New Urbanism and Suburbia with its criticisms of cul-de-sac underlines this particular planning typology. It is anticipated this research paper will contribute to that debate, from a non-western perspective.

The sub-characteristics of both these technical and social characteristics further numerates syntax of interesting questions for further research. It is within these components that a certain pattern and trend has begun to emerge as described by Bajunid, et. al. (2013). Table 3 has merely indicated its descriptive analysis as in degrees of colour coding, in measures of highest quantity or strengths within the 18 culs-de-sac. Further analysis needs to be conducted to extend the meaning to these findings. This is to ensure as in all environment-behaviour studies, that the findings are not conveniently generalised to all culde-sac courtyard neighbourhoods. However, it can be surmised that for the SACC district, these components represents sufficient classification characteristics.

\subsection{Conclusion}

The availability of such designs in Malaysia is mainly limited to cities and townships at the medium density of suburban fringes. These criteria shall be the basis for scaling the research to state and national level. This analysis was able to show some form of classification in the different technical and social characteristics. This shall be able to relate further to environmental psychology and the social dynamics of homeowners that resides within each of this particular variety of a cul-de-sac courtyard. This area of research will require transdisciplinary collaboration of different fields in comprehending the different syntax of the culde-sac and how they affect neighbourhoods. These studies could then better assist policy makers, planners and architects to engage in the design of neighbourhoods in a more holistic approach.

\section{Acknowledgement}

The Author wishes to record thanks to the supervisory committee, industry collaborators and the devoted work of Graduate Research Assistant, Syazwani Abdul Kadir, which was made possible by the Ministry of Higher Education and Universiti Teknologi MARA (UiTM) under the Research Acculturation Grant Scheme (RAGS). An acknowledgement of the unabridged version of the paper could be acquired from Procedia - Social and Behavioural Sciences. 
Ibrahim Bajunid, A.F., et.al. / Asian Journal of Environment-Behaviour Studies (ajE-Bs), 3(10) Sep / Oct 2018 (p.133-141)

Table 3: Cul-de-sac Courtyard Syntax of Shah Alam City Council (Author, June 2013). For complete explanatory notes and detail description on the visuals, please contact the Author or refer to unabridged version of the paper in Procedia - Social and Behavioural Sciences.

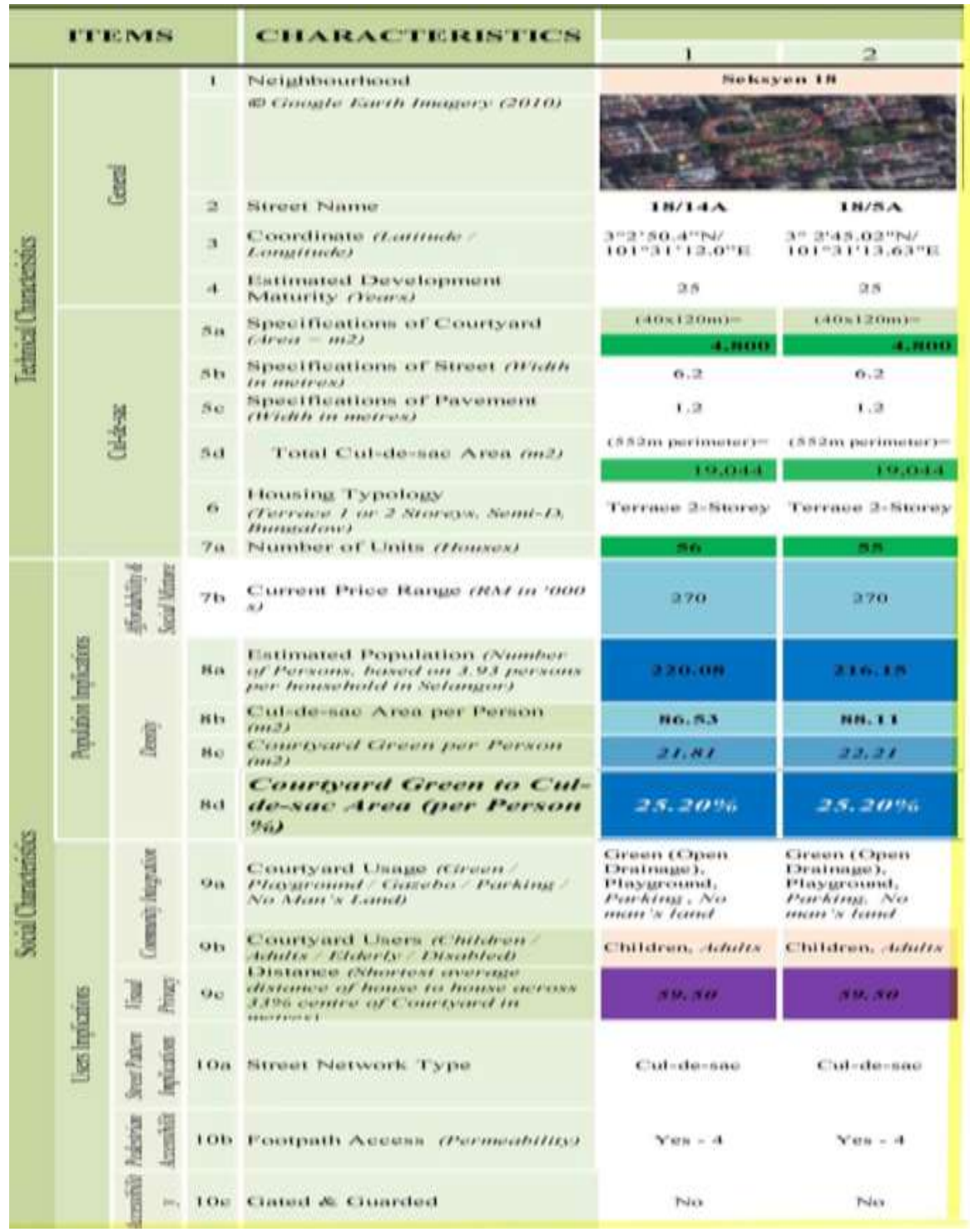

(Source: Table extracted from a larger study from Author, June 2013) 


\section{References}

Asabere, P. K. (1990). The Value of a Neighbourhood Street with Reference to the Cul-de-sac. The Journal of Real Estate Finance and Economics, 3(2), 185-193.

Bajunid, A. F. I., Abbas, M. Y., \& Nawawi, A. H. (2012a). Tessellation Planning: Relationships between the Physical Environment and the Neighbourhood. Asian Journal of Environment-Behaviour Studies, 3(7), 44-56.

Bajunid, A. F. I., Abbas, M. Y., \& Nawawi, A. H. (2012b). Identification Processes of Culs-de-sac in Shah Alam: Preamble to Neighbourhoods' Way of Life. Procedia Social and Behavioral Sciences. 50(2012), 226-237.

Bajunid, A. F. I., Abbas, M. Y., \& Nawawi, A. H. (2012c). Tessellating 'Honeycombs'. Management of Natural Resources, Sustainable Development and Ecological Hazards III, 141-152.

Bajunid, A. F. I., Abbas, M. Y., \& Nawawi, A. H. (2013). Social Cohesion of the Malaysian Cul-de-sac Neighbourhoods: Brief Critical Review of Concepts. Asian Journal of Environment-Behaviour Studies, 4(11), 99107.

Charmes, E. (2010). Cul-de-sacs, Superblocks and Environmental Areas as Supports of Residential Territorialization. Journal of Urban Design, 15(3), 357 - 374.

Cohen, L. B. (2011, 21 March). Boolean Searching on the Internet. Internet Tutorials: Your Basic Guide to the Internet Retrieved 23 March, 2011, from http://www.internettutorials.net/boolean.asp

Cozens, P., \& Hillier, D. (2008). The Shape of Things to Come: New Urbanism, the Grid and the Cul-de-sac. International Planning Studies, 13(1), 51-73.

Davis, M. P., Nordin, N. A., \& Ghazali, M. (2006). Thermal Comfort Honeycomb Housing : An Alternative to Terrace Housing. Universiti Putra Malaysia (UPM): UPM Press.

Federal Department of Town and Country Planning (2011). Garis Panduan Perancangan Perumahan (Draf Kedua 17 Jun 2011). (ISBN 978-983-41729-6-1). Malaysia: Federal Department of Town and Country Planning, Ministry of Housing and Local Government Malaysia.

Ghazali, M., \& Bajunid, A. F. I. (2011). Tessellation Planning and the Small Neighbourhood as an Appropriate Scale for Social Amenities and Engineering Infrastructure to Meet Urban Needs. Paper presented at the 13th International Conference on Humane Habitat (ICHH), Mumbai, India.

Othman, S., \& Said, I. (2012). Affordances of Cul-de-sac in Urban Neighborhoods as Play Spaces for Middle Childhood Children. Procedia - Social and Behavioral Sciences, 38(0), 184-194.

Selangor Department of Town and Country Planning. (2010). Garis Panduan dan Piawaian Perancangan Negeri Selangor (Edisi Kedua). Malaysia: Department of Town and Country Planning, Selangor.

Southworth, M., \& Ben-Joseph, E. (1995). Street Standards and The Shaping of Surburbia. Journal of The American Planning Association, Vol. 61(No. 1), 65-81.

Southworth, M., \& Ben-Joseph, E. (1997). Streets and the Shaping of Towns and Cities. New York: McGraw-Hill

Southworth, M., \& Owens, P. M. (1993). The Evolving Metropolis: Studies of Community, Neighborhood, and Street Form at the Urban Edge. Journal - American Planning Association, 59(3), 271-287. 